\title{
SPECIFIČNI ELEMENTI V FUNKCIJSKI ZGRADBI LJUBLJANE
}

\author{
Mirko Pak \\ Pod vrbami I, 1000 Ljubljana, Slovenija \\ e-mail: mirko.pak@guest.arnes.si
}

\section{Izvleček}

V funkcijski zgradi Ljubljane so v ospredju oskrbne dejavnosti, ki oblikujejo svojo novo mestno omrežje. Posebna pozornost velja štirim velikim oskrbnim središčem in soodvisnosti njihovega razvoja s trgovsko funkcijo v mestnem središču. To so potrdili tudi rezultati ankete, ki so izpostavili tudi vzroke takšnim razvojnim procesom. Ti so v korist velikih nakupovalnih središč v Šiški, Mostah, na Rakovniku in Viču.

Ključne besede: Ljubljana, oskrba, trgovina, vplivna območja, nakupovalna središča, mestno središče.

\section{SPECIFIC ELEMENTS IN THE FUNCTIONAL STRUCTURE OF LJUBLJANA}

\begin{abstract}
The functional structure of Ljubljana is predominated by supply activities which form its own new city network. Particular attention shall be paid to four big supply centres and the interdependence of their development with the commercial function within the city centre. This has also been confirmed on the basis of the results of a questionnaire, with the reasons for the development processes pointed out, which are in favour of the big trade centres in Šiška, Moste, Rakovnik and Vič.
\end{abstract}

Key words: Ljubljana, supply, trade, gravitation area, trade centres, city centre. 


\section{UVOD}

Zadnja desetletja doživljajo mesta "najhitrejši razvoj", če lahko tako označimo ves razvoj in spremembe v ekonomski, socialni in prostorski zgradbi mestnih središč, drugih sklenjeno pozidanih mestnih predelov, predmestij in obmestij, ki doživljajo intenzivno suburbanizacijo.Če so se v preteklosti procesi urbanitacije, suburbanizacije, dezurbanizacije, reurbanizacije, gentrifikacije in drugi v različnih obdobjih in okoljih dogajali dokaj prepoznavno, so ti danes sočasni in soodvisno prisotni v razvoju mest. Takšen razvoj je zajel vse elemente mestne zgradbe od prebivalstva do storitvenih in proizvodnih dejavnost v mestih vseh velikosti in okolij.

Razvoj posameznih elementov mestne zgradbe je vedno bolj soodvisen, pri čemer imajo velik vpliv globalizacijski procesi. Velike firme s svojim kapitalom odločilno krojijo funkcijski razvoj mest, zato se vedno bolj uveljavlja termin "globalno mesto" za velemesta. To se še potencira na področju oskrbnih funkcij. Posledica je vedno bolj prepletena in pestra raba mestnega prostora. Funkcija bivanja se $\mathrm{v}$ mestih vedno bolj prepleta ne le $\mathrm{z}$ oskrbnimi funkcijami, ampak tudi s proizvodnjo. Raba mestnega prostora postaja vedno bolj mnogofunkcionalna in se v vseh svojih elementih tudi naglo spreminja. (Kinkel, 1999)

Lep primer novih oblik suburbanizacije je novo sejemsko naselje na vzhodnem obrobju Münchena. Ob sejemskem predelu sta tam še storitveno-proizvodni in stanovanjski predel in ob tem rekreacijska zona kot četrti funkcijski predel fizično in funkcionalno enotnega naselja.

Ena najbolj razširjenih in vitalnih v mestnem razvoju je oskrbna funkcija, v okviru katere trgovska funkcija nedvomno izstopa. Slednja je svojo strukturo in lokacijo močno spremenila, popestrila svojo pojavnost in pripeljala do novih oblik rabe mestnih zemljišč, oziroma prostora. Če je trgovina na začetku svojih "shopping centrov" privabljala potrošnike na tradicionalne lokacije $\mathrm{v}$ mestnih središčih in na nove na mestnem obrobju, pa se sedanji prostorski razvoj trgovine vse bolj prepleta s prebivalstvom, se mu približuje in funkcijsko ter funkcionalno tudi prilagaja. Vedno več je trgovskih središč, zlasti manjših, na obrobju mestnega središča in v večjih stanovanjskih naseljih. Lokacija trgovskih središč v Ljubljani, $\mathrm{s}$ štirimi osnovnimi zgostitvami na obrobju to nazorno potrjuje. $V$ primeru milijonskih mest kot sta Zagreb in Budimpešta ležijo velika nakupna središča tudi v gosto pozidanem mestnem središču (Tiner, 2001). Tudi nadaljnji razvoj trgovine je primarno usmerjen $v$ štiri velika nakupna središča Ljubljane na škodo vseh manjših nakupovalnih središč in še posebej mestnega središča, tako samega njegovega jedra kot obrobja. Še posebej nazoren tovrstni primer imamo v Mariboru po izgradni Euro parka in nakupnega središča ob Tržaški cesti. Rezultata takšnega razvoja je vedno večja koncentracija, kompleksnost in pestrost v velikih nakupnih središčih, posledično pa nagle spremembe, nadgradnja s storitvami, objekti za prostočasovne aktivnosti in še kaj.

Vzrokov za tako dinamičen in pester razvoj trgovske funkcije je seveda veliko in $v$ posameznih mestnih predelih se precej razlikujejo. Za primer pa navedimo kaj pravi Jörg Maier o vzrokih specifičnega razvoja klasičnega nakupovalnega mestnega središča: (Maier, 2001)

- praznjenje mestnega središča z odseljevanjem prebivalstva, 
- $\quad$ rastoče cene zemljišč in najemnin,

- $\quad$ pomanjkanje primernih površin za širjenje,

- omejevanje številnih urbanih kvalitet,

- $\quad$ zmanjšanje stanovanjskih površin na robu mestnega središča.

Sicer pa lahko v mestih opredelimo tri osnovne lokacije in najbolj aktualne koncentracije trgovine:

- mestno središče v svoji primarni funkciji s sicer širokim izborom vseh vrst trgovin na relativno majhnem prostoru, s koncentracijo specialnih trgovin in z notranjo prostorsko diferenciacijo, še posebej velikih mestih,

- $\quad$ velika nakupovalna središča na mestnem obrobju ali v suburbani zoni,

- $\quad$ kombinacija mestnega središča, nakupovalnih središč na obrobju mestnega središča, v subcentrih pri velikih mestih in v velikih stanovanjskih soseskah.

\section{OSKRBNA FUNKCIJA V LJUBLJANI}

Geografsko zanimanje za proučevanje trgovinske funkcije je povezano s hitro rastjo nakupnih središč, s strukturnimi spremembami v mestnem jedru, še posebej pa z razvojem prostorskih odnosov v zvezi s spremenjenimi osebnimi navadami, vse do analiz prostorskih konfliktov povezanih s problematiko alokacije. (Maier, 2001)

Tudi v Sloveniji sledimo povečanemu zanimanju geografov za problematiko trgovin in nakupnih središč, še posebej v obeh največjih mestih Ljubljani in Mariboru. O tem so pisali V. Drozg v Geografskem vestniku 73/1 (2001), v Arbeitsmaterialien zur Raumordnung und Raumplanung 204 (2001), skupaj z M. Pakom v Arbeitsmaterial ARL 282 (2001) in slednji v Geografiji Ljubljane (2002). Fizične oblike oskrbne funkcije je Drozg tudi kategoriziral v trgovska središča, hipermarkete, velike specializirane trgovine in izloči trgovski kompleks BTC v Ljubljani. Na osnovi tega je leta 2001 v Sloveniji opredelil 61 nakupnih središč v 27 naseljih (Drozg, 2001).

V strokovnem gradivu za pripravo prostorskega plana Mestne občine Ljubljana se govori o naslednjih sedmih vrstah oblik trgovine: supermarket in hipermarket, discont, veleblagovnica, samopostrežna trgovina, prodajalna z mešanim blagom, tržnica. (Trgovina, 2001)

Dejstvo je, da je pri problematiki trgovine, njenega razvoja in funkcioniranja nujno upoštevati tri elemente: gospodarskega, socialnega in z obojim soodvisnega prostorskega, tudi v pogledu fizične zgradbe mesta. Ob tem gre v socialnem pogledu predvsem za kupno moč potrošnika in s tem povezanim nakupnim ravnanjem; pri ekonomskem predvsem za vrednost prostora ter za ustvarjeni promet in pri prostorskem za lokacijo kot takšno in za razmestitev pojava na sploh.

Podobno pomembni so še številni drugi dejavniki od ekonomske politike, splošnih političnih in gospodarskih ter drugo. Spomniti se je treba samo na velike spremembe pogojev za delovanje trgovine v Trstu, Celovcu, Lipnici, pa tudi v Münchenu, ki so nakupne navade in smeri slovenskih kupcev povsem spremenili.

Čim večje je mesto, tem večja je absolutna in relativna koncentracija trgovine, pri čemer še posebej prednjačijo glavna mesta. Tako premore Dunaj tri od petih največjih nakupnih 
središč v Avstriji. Na Dunaju je tudi kar 25 od 100 največjih nakupnih središč v Avstriji s površino $352.000 \mathrm{~m}^{2}$ (Richter, 2001). V Budimpešti pa je bilo leta 1999 osredotočenih nad $80 \%$ vseh nakupnih središč s $680.000 \mathrm{~m}^{2}$ prodajnih površin na Madžarskem (Tiner, 2001).

Manj ekstremno stanje je Drozg ugotovil leta 2001 tudi v Sloveniji, kjer je bilo 16 od 61 nakupnih središč v Ljubljani (Drozg, 2001). Njihova razmestitev je vidna iz karte1 in je $\mathrm{v}$ veliki meri vezana na tradicionalna nakupna središča. Pri tem sta lokacija nakupnih središč in prebivalstva $\mathrm{v}$ izrazito pozitivnem odnosu (Pak, 2002).

Podobno kot drugod, se je tudi v Ljubljani trgovina močno pomnožila in prostorsko razširila. Njena površina se je povečala na $327.000 \mathrm{~m}^{2}$, število prodajaln se je v 10 letih (1992 - 2000) povečalo za 63,9\% na 3.273, potem ko se je po višku leta 1997 število prodajaln v štirih letih zmanjšalo za $15 \%$ (Stare, 2003 )

Ves proces številčnega, kakovostnega in prostorskega razvoja trgovine kaže na prostorsko koncentracijo, na krepitev velikih trgovskih podjetij in na večanje števila velikih prodajaln. Za Bežigradom in v Centru število prodajaln nazaduje, v Mostah, Šiški in na Viču pa se njihovo število počasi povečuje.

Podobno je $\mathrm{z}$ ustvarjenim prometom, ki je v Ljubljani za tretjino višji kot je v Sloveniji. To še najbolj realno kaže stanje trgovine $v$ Ljubljani. $V$ štirih letih se je promet $v$ ljubljanskih trgovinah povečal za 41,4\%, v Sloveniji pa za $34,6 \%$. V Centru je promet upadel za 15,6\% kar potrjuje, da doživlja trgovina v mestnem središču krizo in zanjo zaenkrat ustreznih rešitev še ni, tudi $v$ večini tujih mest ne. To odseva tudi v njenih strukturnih spremembah, ki ustreznih rešitev še ni našla. Zaradi BTC se je promet najbolj povečal v Mostah, nekoliko manj pa za Bežigradom. Povečal se je promet tudi na Viču, v Šiški z novim nakupovalnim središčem Mercator pa za manj kot 10\% (Letni pregled, 1997 in 2001).

Podobno kot drugod lahko tudi v Ljubljani ugotovimo tri vrste zgostitve trgovine: mestno središče v celoti, lokalna oskrbna središča in velika oskrbna središča. Pri tem so lahko lokalna oskrbna središča zelo raznolika in praviloma so vezana na gosto poseljeno lokalno prebivalstvo.Kjer tega ni, $\mathrm{v}$ zadnjih petnajstih letih nastala sredičča niso dosegla pričakovanega prometa. Med slednjimi najbolj izstopajo oskrbni centri Murgle, Ledina, WTC. Posledica je visok in vedno večji delež praznih lokalov, naglo spreminjanje rabe, rast števila gostinskih obratov, pisarn in podobno.

Ob upoštevanju vseh pomembnejših zgostitev trgovinskih obratov naj bi bilo v Ljubljani 29 oskrbnih središč, od tega 16 središč sosesk, 7 ožjega mestnega in 5 širšega regionalnega pomena (Karta 1). Od slednjih je BTC svoj močnejši vpliv razširil na vso Ljubljansko urbano regijo, sicer pa na vso Slovenijo. Jasne meje med navedenimi skupinami je težko določiti, še posebej pa spodnje meje do vedno številnejših lokalnih zgostitev trgovinskih, oziroma oskrbnih obratov (Pak, 2002). ${ }^{1}$

$\mathrm{V}$ strokovni in aplikativni literaturi se uporabljajo vsi termini glede na namen in predmet obravnave: trgovski, nakupni, oskrbni. Načeloma se termin trgovski uporablja pri obravnavi trgovine kot take, nakupni v primeru potrošnje in kupcev ter gravitacije, oskrbni pa v primeru obravnave ob trgovini tudi drugih oskrbnih dejavnosti.

\footnotetext{
${ }^{1} \mathrm{~V}$ strokovni in aplikativni literaturi se uporabljajo vsi termini glede na namen in predmet obravnave: trgovski, nakupni, oskrbni. Načeloma se termin trgovski uporablja pri obravnavi trgovine kot take, nakupni v primeru potrošnje in kupcev ter gravitacije, oskrbni pa v primeru obravnave ob trgovini tudi drugih oskrbnih dejavnosti.
} 
Oskrbne in storitvene dejavnosti se vse bolj selijo tudi k glavnim prometnicam, s čimer njihova funkcija lokalne oskrbe prerašča $\mathrm{v}$ mestno in deloma tudi regijsko oskrbno funkcijo. Po svoji oskrbno-storitveni opremljenosti izstopajo tri ljubljanske vpadnice, Dunajska, Celovška in Tržaška cesta. Njihov različen funkcijski razvoj v preteklih letih se je zadnja leta močno okrepil s tem, da se na eni strani poglablja njihova funkcijska usmerjenost ob hkratno povečani funkcijski pestrosti, med drugim tudi s stanovanjsko funkcijo.

Ob Dunajski cesti se krepi in širi poslovno središče Ljubljane vse do Ruskega carja na severu. Leta 2000 je bila tretjina poslopij nestanovanjskih in nadaljnjih $40 \%$ je bilo mešane stanovanjsko-nestanovanjske rabe. (Pavlič, 2000). Zadnja štiri leta zgrajene poslovne zgradbe so to razmerje še močno nagnile na stran nestanovanjske rabe. Naglo se terciarizira raba prostora ob Tržaški cesti. Prosta zemljišča in velik interes usmerjata sem zelo raznovrstne dejavnosti pri čemer poleg servisnih dejavnosti izstopajo še poslovne, trgovske ter stanovanjska raba prostora.

Večja in še posebej velika oskrbna središča postajajo vse bol mnogofunkcionalna. Dober primer je BTC s kino kompleksom Kolosej in načrtovanimi vodnimi objekti, ki bodo namenjeni preživljanju prostega časa, povezano s funkcijo potrošnje. Zlasti na primernih površinah na obrobju mesta se razvijajo funkcijsko zelo raznoliki predeli, ki jih je težko opredeliti za klasične oskrbne predele. Ob trgovini, storitvah, obrti in drugem se je tukaj naselila tudi proizvodnja. Značilen takšen primer je predel med Koprsko in Tbilisijsko cesto na Viču (Pak, 2002).

\section{ANALIZA ANKETE V VELIKIH LJUBLJANSKIH NAKUPOVALNIH SREDIŠČIH}

Čeprav sta bili doslej opravljeni dve podrobnejši analizi nekaterih elementov nakupovalnih središč v Ljubljani (Trgovina, 2001; Stare, 2003), je leta 2004 opravljeno proučevanje štirih največjih nakupovalnih središč, City centra v BTC, Leclerc na Rudniku, Interspar na Viču in Mercator v Ššski, dosedanje ugotovitve potrdilo in nekatere tudi dopolnilo. ${ }^{2}$

In čeprav se je naslonilo $\mathrm{v}$ glavnem na anketo potrošnikov, je pokazalo tudi na nekatere širše probleme trgovske funkcije $v$ Ljubljani in še posebej v odnosu največjih štirih nakupovalnih središč do mestnega središča.

Prometna lokacija je eden osnovnih dejavnikov uspešnosti velikih nakupovalnih središč. Njihovo vplivno območje praviloma presega lokalne in tudi mestne potrebe. Zato pomeni ljubljanski avtocestni obroč za vsa štiri nakupovalna središča osnovno prometno povezavo, ki ob siceršnjem prevladujočem vplivu v smeri lokacije nakupovalnih središč, pogosteje privablja potrošnike v vsa štiri središča tudi iz drugih delov mesta, obmestja ali celo iz širše regije. V slednje pa spada vsa Ljubljanska urbana regija, kar pomeni pogostejšo ali redkejšo gravitacijo vsaj pol milijona prebivalcev v oddaljenosti $60 \mathrm{~km}$. Za gravitaci-

\footnotetext{
${ }^{2}$ Leta 2003 so slušatelji 3. letnika geografije na Filozofski fakulteti v Ljubljani, študijske usmeritve regionalno planiranje, opravili pod vodstvom avtorja članka, terensko raziskavo trgovskih središč v Ljubljani, Mariboru, Kranju in na Ptuju ter kratko analizo zbranega gradiva.
} 
jo kupcev v posameznih trgovinah sicer občasno zbirajo podatke, ki pa so na voljo le za interno uporabo in jih ni bilo mogoče pridobiti. Analiza porekla parkiranih avtomobilov pa je vendarle pokazala nekatere skupne značilnosti, pa tudi razlike med nakupovalnimi središči glede porekla kupcev. Okrog $75 \%$ je bilo avtomobilov z ljubljansko registracijo in med temi $50 \%$ iz Ljubljane same in le okrog $15 \%$ iz sosednjih občin. Izstopa višji delež avtomobilov s kranjsko registracijo pri čemer je zanimivo, da nihče od anketiranih ne obiskuje nakupovalna središča izven Ljubljane. Gravitacija je torej izključno enosmerna, kar je seveda v korist ljubljanskih nakupovalnih središč in osnova za njihov nadaljnji razvoj in $\mathrm{v}$ škodo nakupovalnih središč ne le izven Ljubljane, temveč tudi manjših nakupovalnih središčih v Ljubljani sami.

Kot je bilo že omenjeno, lokacija vsakega od štirih velikih nakupovalnih središč vpliva na oblikovanje njihovih vplivnih območij. Poseben gravitacijski model pa ima BTC, kamor pogosteje gravitirajo prebivalci različnih predelov Ljubljanske urbane regije. Za to sta dva motiva, mnogo večja in tudi bolj specializirana ponudba celotnega oskrbnega središča BTC in njegova atraktivnost, ki se kaže tudi $\mathrm{v}$ znatnejši funkciji preživljanja prostega časa. Center obiskujejo tudi številni obiskovalci brez nakupovalnih namer. Sicer pa primer City parka, ki je bil odprt leta 2002 in premore $97.000 \mathrm{~m}^{2}$, od tega $25.000 \mathrm{~m}^{2}$ prodajnih površin in bo z izgradnjo garažne hiše imel okoli 2.600 parkirnih mest, gornje navedbe potrjuje. Drugo leto obratovanja City parka (2003) je promet skoraj za petino presegel pričakovanja. 74 trgovskih lokalov je obiskalo 7,2 milijona kupcev in ustvarilo 30 milijard tolarjev prometa. $\mathrm{Ob}$ tem je treba izpostaviti atraktivnost marketa (velike trgovine za vsakodnevno oskrbo), ki ima podobno kot $\mathrm{v}$ drugih evropskih nakupnih središčih vsaj pomembno če že ne primarno vlogo privlačnosti ponudbe. Podobne so izkušnje v nakupnih centrih $\mathrm{v}$ tujini. Zaradi upadanja prometa bodo na primer največje nakupno središče na jugu Gradca dopolnili z velikim marketom.

Obisk nakupovalnih središč je odvisen, morda celo v največji meri, od njihove privlačnosti, ki je odvisna od cele vrste dejavnikov. Med temi je opremljenost nakupnih središč, ki se manifestira v njihovi ponudbi, na prvem mestu. Ponudbo pa sestavlja vrsta elementov od števila in velikosti ter opremljenosti trgovin, do njihove strukture, zgoščenosti (lokacije $\mathrm{v}$ okviru centra), cen, parkirnih možnosti in drugega. Ne glede na dograjevanje velikih ljubljanskih nakupoalnih središč ta sama zaenkrat ne čutijo večjih problemov, ki se zaenkrat kažejo, kot že rečeno, v manjših nakupnih središčih in v samem mestnem središču. So pa v tujini že znani številni primeri krize velikih novih nakupovalnih središč zaradi gradnje novih ali naglega večanja obstoječih nakupovalnih središč. Do tega bo prišlo tudi v Ljubljani in v nekaterih drugih slovenskih mestih. Morda je vprašljiva že gradnja drugega nakupovalnega središča na nekdanjem sejemskem prostoru na robu mestnega središča v Kranju?

Med prednostmi, ki jih imajo nakupna središča, je na splošno daleč izpostavljeno parkiranje, ki pa ponekod ob nakupovalnih konicah že doživlja težave. Vsa štiri ljubljanska nakupovalna središča zahtevajo avtomobilski dostop in zato je ob parkiriščih splošna dostopnost prav tako pomembna kot drugi zgoraj našteti dejavniki. Podobno pomembna sta ponudba, oziroma izbira in gostota trgovin. Med dejavniki manj izstopajo cene, odnos do kupcev, spremljajoča ponudba in drugo. Sicer pa vsi anketirani postavljajo štiri velika nakupovalna središča pred manjša in pred mestno središče kot nakupovalno središče. 
Slika 1: Oskrbna središča

Figure 1: Supply centers

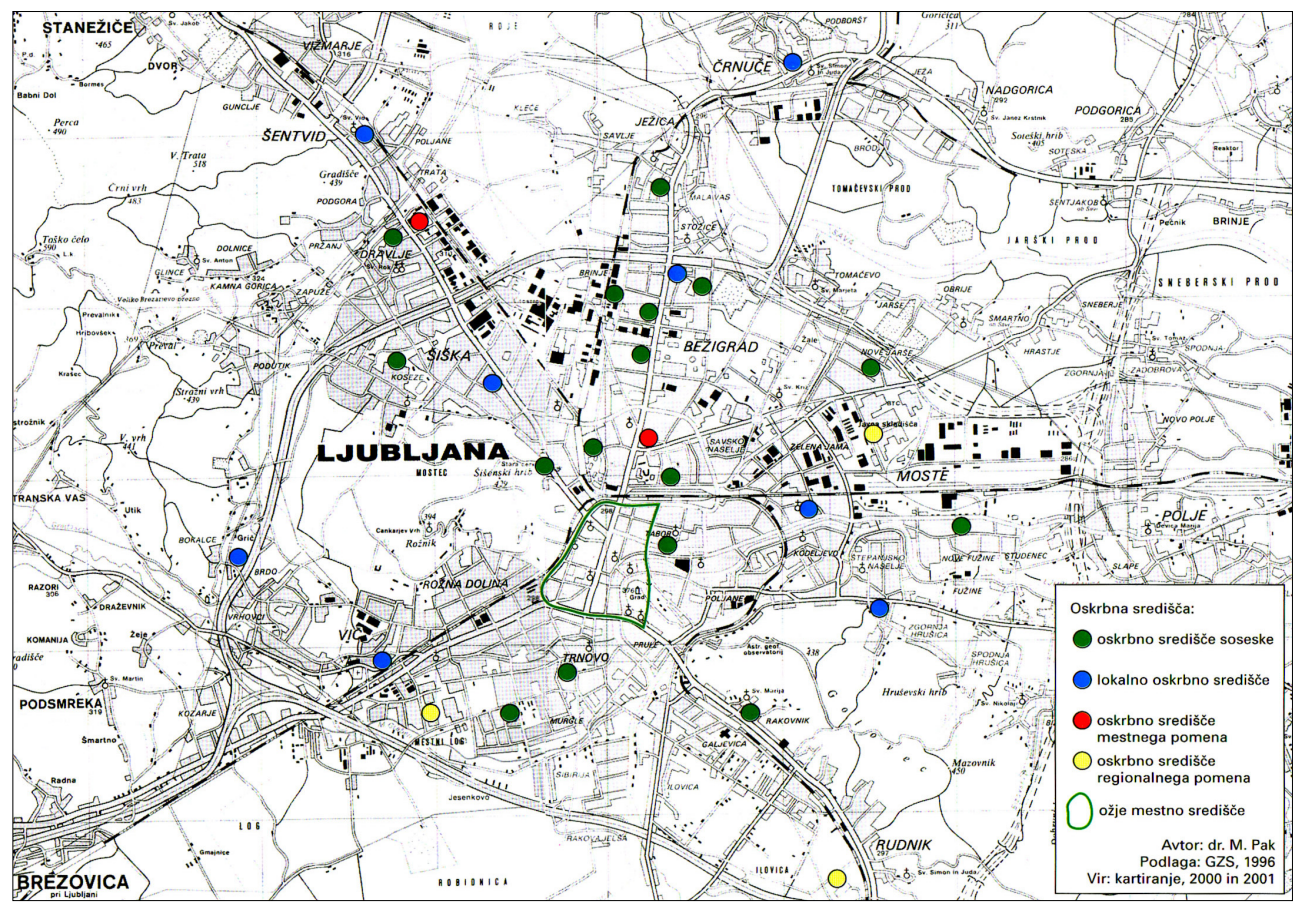

Obratno vprašanje o pomanjkljivostih nakupovalnih središč je pričakovano izpostavilo premalo izbiro in ponudbo, ki se sicer prikazuje kot pozitivna kategorija. Ob tem se misli na številnejše trgovine s podobno ponudbo, ki so značilne za mestno središče. Med nakupovalnimi središči je bilo najmanj negativnih odgovorov v BTC kar pomeni, da je stanje v pozitivni soodvisnosti z velikostjo nakupovalnega središča. Vsi drugi odgovori o pomanjkljivosti nakupovalnih središč številčno močno zaostajajo in so si podobni. Kot moteč element izstopajo gneča, zasedenost parkirišč in izguba časa.

Glede na pogostost obiskov, oziroma nakupov v velikih oskrbnih središčih Ljubljane, število obiskovalcev in ustvarjeni promet, se je iz lokalnih trgovin in trgovskih središč v velika trgovska središča močno preusmerila tako tedenska kot dnevna oskrba. $V$ ta središča gravitira tudi prebivalstvo širše okolice, zlasti iz vedno gosteje poseljene suburbane zone. Dostopnost, koncentracija trgovin (velikih) in obsežna parkirišča pa so nedvomno osnovni motiv takšnemu stanju in takšnim razvojnim procesom.

Soodvisnost trgovin v velikih nakupovalnih središčih in v mestnem središču je velika in se povečuje. Nakupna središča z vedno številnejšimi netrgovinskimi dejavnostmi podaljšujejo čas, ki ga v njih prebijejo obiskovalci. Obisk mestnega središča, ki se mu lahko pridruži tudi nakupovanje, oziroma je namenjen kupovanju, je vedno pogosteje povezan z drugimi motivi: največ z drugimi opravki, bistveno pa zaostajajo sprehod, tranzit in razne storitve. Le $12 \%$ anketiranih je obisk mestnega središča namenilo prvenstveno nakupovanju. 
Slika 2: Funkcijska raba $v$ Stari Ljubljani

Figure 2: Functional use in Ljubljana down town

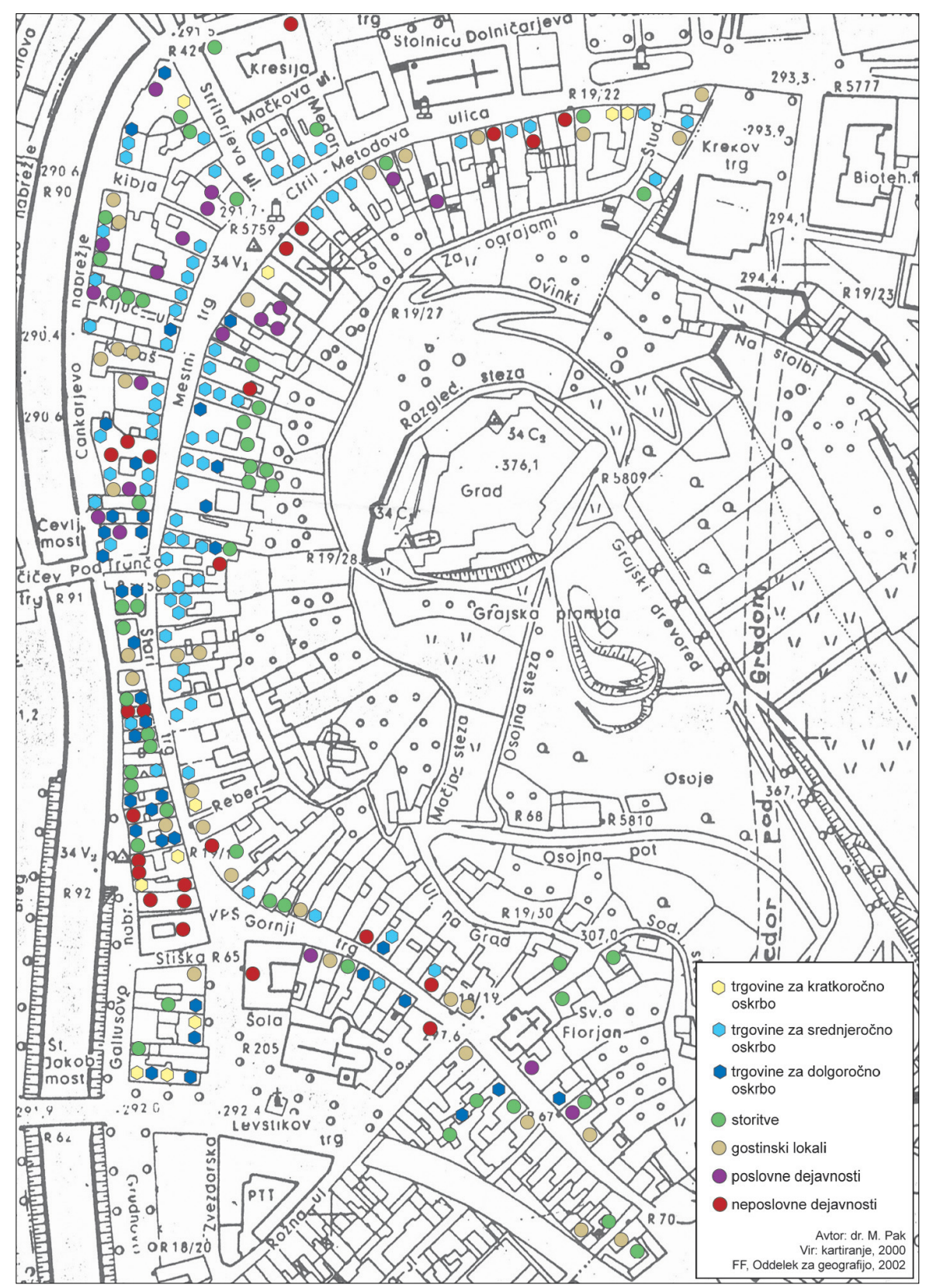

Tudi Staretova študija o Ljubljani in raziskava v Mariboru sta pokazala na značilnosti delovanja trgovine $\mathrm{v}$ mestnem središču, ki naj bi bila praviloma namenjena prebivalstvu vsega mes- 
ta. Ob močno zmanjšanem številu obiskovalcev in s tem tudi kupcev, četrtina trgovin naj ne bi bila prizadeta $\mathrm{s}$ širitvijo trgovine na mestnem obrobju. V starem mestnem jedru Ljublja-ne je takšnih trgovin le 17\% (Stare, 2003). Dosedanja proučevanja rabe srednjeveškega jedra Ljubljane so pokazala, da se je število trgovinskih obratov sicer povečevalo in prostorsko razširilo na dvorišča in proti Gornjemu trgu (Karta 2). Pokazalo pa je tudi na njihovo specializacijo, na povezanost s turističnim obiskom, $\mathrm{z}$ nekaterimi drugimi funkcijami tega dela mesta in na dokaj skromen promet. Nestabilno stanje potrjuje tudi naglo spreminjanje trgovin in le skromni poskusi njihovega širjenja na obrobje proti Gornjemu trgu.

\section{SKLEPNE UGOTOVITVE}

Velika nakupovalna središča v Ljubljani imajo funkcijo oskrbe tako mestnega predela kot celega mesta in celo širše regije v primeru BTC. Bolj ali manj pa je to prisotno tudi pri ostalih treh središčih, odvisno od primerne prometne dostopnosti, ki jo je avtocestni obroč okoli Ljubljane v veliki meri zagotovil.

Trgovska funkcija in še posebej trgovska središča so povezana $\mathrm{z}$ gostim prometom. Izstopa funkcija parkirnih površin, ki je močno v prid nakupnih središč na mestnem obrobju. Velik del anketnih odgovorov je opozorilo na potrebo po parkirnih površinah v mestnem središču, oziroma po parkirnih hišah. Za nujnost tega je lep primer izredno živahna glavna trgovska cesta v Münchenu, kjer garažne hiše v stranskih ulicah nudijo obilo parkirnih mest.

Za uspešno obratovanje nakupovalnega središča je nujna določena struktura ponudbe, oziroma trgovin. V ospredju je ustrezno velik market, obiskovalci pa pogosto pogrešajo še nekatere storitve kot banke, PTT, lekarne in drugo. Glede na doseženi značaj štirih velikih nakupnovalnih središč v Ljubljani, ki imajo v veliki meri funkcijo vsakodnevne oskrbe, je opremljenost s storitvami povezana $\mathrm{z}$ razpoložljivim časom obiskovalcev. Porabljeni čas postaja vse pomembnejši dejavnik odločanja o oskrbovanju. Po anketnih odgovorih se daje prednost velikim nakupovalnim središčem pred mestnim središčem.

Med funkcijami je za uspešnost poslovnega središča vedno pomembnejša funkcija preživljanja prostega časa. Medtem ko se v marsikaterem manjšem nakupnem središču število gostinskih lokalov povečuje, kar velja tudi za vse predele središča Ljubljane, pa si v BTC obetajo večji obisk in promet tudi $\mathrm{z}$ namestitvijo drugih objektov za preživljanje prostega časa.

V mestnem središču število trgovin nazaduje in trgovina se prostorsko ne širi več. Nekdaj tipične trgovske ceste izgubljajo na svojem pomenu, kot je to v primeru dela Dunajske ceste in okolice mestnega predela Ajdovščina. Struktura trgovin je večkrat neustrezna, trgovske ceste pa niso več tako homogene kot pred desetimi leti. Na visoko vrednem zemljišču stojijo po svoji rabi malo vredni objekti. Takšen primer je tudi Čopova cesta. V bistvu pa je stanje dokaj nejasno, saj je mestna politika na tem področju nedorečena.

Visoke cene zemljišč in najemnin v središču mesta niso v skladu s strukturo trgovin, tudi ne s številnimi praznimi lokali, ki niso vedno posledica denacionalizacije. Središče Ljubljane naj bi bilo dovolj atraktivno za obiskovalce, ki opravljajo nujne poti skozi mestno središče in za preživljanje prostega časa in ne le za turiste. Nedvomno vrsta trgovin v mestnem središču ne posluje uspešno, kar vodi k nadaljnjemu nazadovanju trgovine v mestnem središču na eni in njeni krepitvi v obrobnih oskrbnih središčih na drugi strani. 


\section{Literatura}

Drozg, V., 2001: Nakupovalna središča v Sloveniji. Geografski vestnik 73-1, Ljubljana, 9 - 21.

Drozg, V., Pak, M., 2000: Einkaufzentren in Slowenien. Arbeitsmaterial ARL 282, Hannover, $187-192$.

Drozg, V., 2001a: Versuch der Bestimmung eines Entwicklungskonzepts von Einkaufszentren in Slowenien. Arbeitsmaterialien zur Raumordnung und Raumplanung 204, Bayreuth, $81-92$.

Kinkel, O., 1999: Spillover Effekte als Teil der Stadt-Umland-Problematik am Beispiel der Stadt Frankfurt am Main und Ihres "Speckgürtels". DELA 14, Ljubljana, 209 - 220.

Letni popis trgovine 1997 in 2001. Ljubljana.

Maier, J., Hessman D., 2001: Einzelhandel und neue Entwicklungen aus der Sicht der geographie und Regionalforschung. Arbeitsmaterialien zur Raumordnung und Raumplanung 204, Bayreuth, $1-14$.

Pak, M., 2001: Rumordnungspolitische und planungspolitische Behandlung des Einzelhandels in Slowenien. Arbeitsmaterialien ARL 282, Hannover, 183 - 186.

Pak, M., 2002: Funkcijska zgradba Ljubljane. Geografija Ljubljane, Ljubljana, 133 - 149.

Stare, F., 2003: Grossflächige Einzelhandelsstandorte in Ortsrandlagen vs. innenstädtischen Einzelhandel. München, dilpomska naloga na TH Müchen.

Tinner, T., 2001: Budapest: Towards the city of Malls? Shopping Cebtre Construction and their Effects on urban Development. Arbeitsmaterialien ARL 282, Hannover, 167-175.

Trgovina. Strokovna gradiva. Ljubljana, 2001.

\section{SPECIFIC ELEMENTS IN THE FUNCTIONAL STRUCTURE OF LJUBLJANA}

\section{Summary}

In the recent years also Slovene cities have experienced rapid structural, functional and social development, with Ljubljana in the first place. Undoubtedly, rapid growth of supply infrastructure is considered to be the most significant change. Supply (trade, shopping) centres are strengthening, some of them at the cities' outskirts being very big and becoming even bigger. The growth of such centres goes usually on the account of smaller supply centres and city centres as classical shopping centres.

Ljubljana with its 270,000 inhabitants, of which 500,000 living in the city region, hosts 16 from 61 shopping centres in Slovenia. Four such big shopping centres are pointing out, attracting not only the inhabitants of Ljubljana but also of the whole region. Almost the whole Slovenia gravitates towards the biggest shopping centre in Slovenia - BTC (Blagovno trgovski center) (Merchandise Trading Centre). Supply activities are subject to rapid development also along the biggest radial roads (traffic routes), namely City along Dunajska cesta, and rather mixed functions, predominated by service activities, along Tržaška cesta. 
A questionnaire which was carried out in big shopping centres in Ljubljana, Maribor, Kranj and Ptuj indicated the significance of the centres' traffic position as well as of sufficient number of parking areas. However, this is considered the biggest problem of all city centres. Shopping centres are, furtheron, privileged by their good equipment, offer and large assortment. Therefore all big shopping centres, in Slovene cities located by the rule at the fringe of continually built-up areas, still keep on growing, making their contribution to specific supply habits of Slovene inhabitants, who visit such centres at least once a week. These centres take over, to a large extent, also the function of every-day supply centres. 